\title{
Over diagnosis of chronic obstructive pulmonary disease in an underserved patient population
}

This article was published in the following Dove Press journal:

International Journal of COPD

II November 2013

Number of times this article has been viewed

\author{
Christian Ghattas' \\ Allen Dai ${ }^{2}$ \\ David J Gemmel ${ }^{3}$ \\ Magdi H Awad ${ }^{2}$ \\ 'Department of Internal Medicine, \\ St Elizabeth Health Center, \\ Youngstown, $\mathrm{OH}, \mathrm{USA} ;{ }^{2}$ Northeast \\ Ohio Medical University College \\ of Pharmacy, Rootstown, OH, USA \\ ${ }^{3}$ Department of Medical Education \\ and Research, St Elizabeth Health \\ Center, Youngstown, OH, USA
}

Correspondence: Christian Ghattas Department of Internal Medicine, St Elizabeth Health Center, 1044 Belmont Ave, Youngstown, OH 44504, USA Tel + I 3305505524

Email christianghattas@gmail.com
Introduction: While cross-national studies have documented rates of chronic obstructive pulmonary disease (COPD) misdiagnosis among patients in primary care, US studies are scarce. Studies investigating diagnosis among uninsured patients are lacking.

Objective: The purpose of this study is to identify patients who are over diagnosed and thus, mistreated, for COPD in a federally qualified health center.

Methods: A descriptive study was conducted for a retrospective cohort from February 2011 to June 2012. Spirometry was performed by trained personnel following American Thoracic Society recommendations. Patients were referred for spirometry to confirm previous COPD diagnosis or to assess uncontrolled COPD symptoms. Airway obstruction was defined as a forced expiratory volume in the first second of expiration $\left(\mathrm{FEV}_{1}\right)$ to forced vital capacity ratio less than 0.7. Reversibility was defined as a postbronchodilator increase in $\mathrm{FEV}_{1}$ greater than $200 \mathrm{~mL}$ and greater than $12 \%$.

Results: Eighty patients treated for a previous diagnosis of COPD $(n=72)$ or on anticholinergic inhalers $(n=8)$ with no COPD diagnosis were evaluated. The average age was 52.9 years; $71 \%$ were uninsured. Only $17.5 \%$ (14/80) of patients reported previous spirometry. Spirometry revealed that $42.5 \%$ had no obstruction, $22.5 \%$ had reversible obstruction, and $35 \%$ had nonreversible obstruction.

Conclusion: Symptoms and smoking history are insufficient to diagnose COPD. Prevalence of COPD over diagnosis among uninsured patient populations may be higher than previously reported. Confirming previous COPD diagnosis with spirometry is essential to avoid unnecessary and potentially harmful treatment.

Keywords: chronic obstructive pulmonary disease, COPD, misdiagnosis, over diagnosis, spirometry, uninsured, underserved

\section{Introduction}

Chronic obstructive pulmonary disease (COPD) is a common, preventable, and treatable disease characterized by progressive airflow limitation. Associated with airway chronic inflammatory response and by lung noxiousness to particles or gases, COPD is the third leading cause of death in the US and has an estimated worldwide prevalence of $10 \%$ in people over 40 years. ${ }^{1}$ The annual cost of treatment per COPD patient in the US is $\$ 4,119$ (USD); additionally, indirect nonmedical care costs of $\$ 1,527$ (USD) per patient are known. ${ }^{2}$ While other leading causes of death in the US have declined steadily, COPD death rates have doubled since $1970 .^{3}$

COPD disproportionately afflicts those of lower socioeconomic status and older adults, creating reluctance to diagnose and treat patients. ${ }^{4}$ The Global Initiative for 
Chronic Obstructive Lung Disease report in 2011, emphasizing the significance of this disease, confirmed that spirometry is a requirement for COPD case definition. ${ }^{5}$

Spirometry has the distinct advantage of being a reproducible measurement of lung function that is superior to peak expiratory flow because of greater reliability and specificity. ${ }^{6}$ Symptom based and clinical diagnosis contributes to misdiagnosis and mistreatment. ${ }^{7,8}$ Additionally, spirometry can distinguish between asthma and COPD. ${ }^{9}$

Only one US study has investigated the prevalence of COPD misdiagnosis with spirometry. ${ }^{10}$ However, generalizability of this study was limited: patients were gathered from primary care practices in Colorado and Scotland..$^{10}$ Studies investigating COPD diagnosis among the uninsured are absent. The purpose of this study is to evaluate clinically diagnosed COPD patients with spirometry to ascertain COPD misdiagnosis in an underserved population.

\section{Methods}

A descriptive study was conducted at a federally qualified health center following institutional review board approval. The retrospective cohort from February 2011 to June 2012 included all patients who were referred by primary care providers for spirometry testing available at the health center to confirm a previous COPD diagnosis or for better management of uncontrolled COPD symptoms. Spirometry was done according to procedures recommended by the American Thoracic Society using the Burdick SpiroCard ${ }^{\circledR}$ (Cardiac Science, Hannover, Germany). ${ }^{11}$ Spirometry for each patient was performed by personnel who had undergone training on how to use the spirometry program. Personnel were also trained on device calibration, as well as recording all procedure relevant data. A series of questions was asked to the patients to identify contraindications for spirometry testing. Patients with acute respiratory illness were rescheduled after infection resolution and symptom improvement. All referred patients did not use a short acting beta agonist within 6 hours, a long acting beta agonist within 12 hours, ipratropium within 6 hours, tiotropium within 24 hours, or theophylline within 24 hours of the test. A forced expiratory volume in the first second of expiration to forced vital capacity $\left(\mathrm{FEV}_{1} / \mathrm{FVC}\right)$ ratio above or equal to 0.7 was designated as no obstruction. ${ }^{5} \mathrm{FEV}_{1} / \mathrm{FVC}$ ratio below 0.7 required further evaluation with postbronchodilator testing.

For postbronchodilator testing, $400 \mu \mathrm{g}$ of beta 2 agonist (albuterol) with a spacer was administered. Following the administration of the beta2 agonist and a 15 minute waiting period, postbronchodilator spirometry values were reassessed. Increased $\mathrm{FEV}_{1}>12 \%$ and $>200 \mathrm{~mL}$ when compared with baseline confirmed reversibility. ${ }^{12}$

Patients were categorized as either no obstruction, reversible obstruction, or nonreversible obstruction. Differences by age and pack year history for each group were assessed using analysis of variance and tabulation of mean and standard deviation. Statistical significance was assumed at $P \leq 0.05$.

\section{Results}

Eighty patients were referred for spirometry testing. Out of the 80 patients referred, 72 had a previous diagnosis of COPD (72 out of 444 patients at the clinic) and eight were on anticholinergic inhalers but had no previous COPD diagnosis (eight out of 51 patients at the clinic). The average age was $52.9 \pm 7.7$ years. The majority of patients were self-pay patients (71.3\%), Caucasians (88.8\%), and females $(60 \%)$. Across all patients, average pack years was $37.9 \pm 26.1$. Five patients in this study never smoked, three had previous COPD diagnosis, and two were on anticholinergic inhalers but had no previous COPD diagnosis. All five patients had spirometry results consistent with no obstruction. In the group of patients with previous COPD diagnosis, three patients claimed that COPD diagnosis was made prior to the age of 35 years. Spirometry results showed no obstruction for two of those patients and reversible obstruction for the third patient. Additionally, in the group of patients with previous COPD diagnosis, 18 patients did not remember when they were first diagnosed with COPD, and only 14 patients remembered having spirometry or pulmonary function testing. Table 1 includes all characteristics of patients referred for spirometry.

Spirometry revealed 34 patients $(42.5 \%)$ with no obstruction, 18 patients $(22.5 \%)$ with reversible obstruction, and 28 patients (35\%) with nonreversible obstruction (Figure 1). Younger patients $(P=0.004)$ and patients who had fewer pack years of exposure $(P=0.013)$ were more likely to be in the no obstruction group. Patients in the nonreversible obstruction group were more likely to be older and had 1.7 times more tobacco exposure.

\section{Discussion}

Spirometry confirms COPD diagnosis in the primary care setting. ${ }^{13-15}$ However, a Vermont survey found that only $66 \%$ of primary care respondents owned a spirometer and that spirometry was only performed on half of COPD patients. ${ }^{16}$ In our study, only 14 patients $(17.5 \%)$ reported a previous spirometry or pulmonary function testing. When spirometry 
Table I Characteristics of patients referred for spirometry

\begin{tabular}{|c|c|c|c|c|}
\hline \multirow[t]{2}{*}{ Characteristics } & \multirow{2}{*}{$\begin{array}{l}\text { All patients } \\
(n=80)\end{array}$} & \multicolumn{3}{|c|}{ Spirometry results } \\
\hline & & $\begin{array}{l}\text { No obstruction } \\
(n=34)\end{array}$ & $\begin{array}{l}\text { Reversible } \\
\text { obstruction } \\
(n=18)\end{array}$ & $\begin{array}{l}\text { Nonreversible } \\
\text { obstruction } \\
(n=28)\end{array}$ \\
\hline Age, years (mean \pm standard deviation) & $52.9 \pm 7.7$ & $50.5 \pm 7.9$ & $51.7 \pm 6.9$ & $56.7 \pm 6.8$ \\
\hline Male (n, \%) & $32(40.0)$ & $12(35.3)$ & $10(55.6)$ & $10(35.7)$ \\
\hline \multicolumn{5}{|l|}{ Insurance status (n, \%) } \\
\hline Self-pay & $57(71.3)$ & $22(64.7)$ & $17(94.4)$ & $18(64.3)$ \\
\hline Medicaid & $12(15.0)$ & $7(20.6)$ & I (5.6) & $4(14.3)$ \\
\hline Private insurance & $\mathrm{I}(\mathrm{I} .3)$ & $0(0.0)$ & $0(0.0)$ & I (3.6) \\
\hline Medicare & $10(12.5)$ & $5(14.7)$ & $0(0.0)$ & $5(17.9)$ \\
\hline \multicolumn{5}{|l|}{ Race (n, \%) } \\
\hline Caucasian & 71 (88.8) & $29(85.3)$ & $17(94.4)$ & $25(89.3)$ \\
\hline African American & $8(10.0)$ & $5(14.7)$ & I (5.6) & $2(7.1)$ \\
\hline Native American & $\mathrm{I}(\mathrm{I} .3)$ & $0(0.0)$ & $0(0.0)$ & I (3.6) \\
\hline Smoking history (pack years \pm standard deviation) & $37.9 \pm 26.1$ & $28.3 \pm 21.7$ & $42.2 \pm 23.0$ & $46.8 \pm 29.5$ \\
\hline \multicolumn{5}{|l|}{ Inhalers $(\mathrm{n}, \%)$} \\
\hline LABA and ICS & $46(57.5)$ & $17(50.0)$ & $12(66.7)$ & $17(60.7)$ \\
\hline LABA & $5(6.3)$ & $2(5.9)$ & $\mathrm{I}(5.6)$ & $2(7.1)$ \\
\hline Beta2 agonist & $73(91.3)$ & $30(88.2)$ & $18(100.0)$ & $25(89.3)$ \\
\hline Anticholinergic and beta 2 agonist & II (I3.8) & $5(14.7)$ & $2(I I . I)$ & $4(14.3)$ \\
\hline Anticholinergic (short) & $5(6.3)$ & $3(8.8)$ & I (5.6) & $I(3.6)$ \\
\hline Anticholinergic (long) & $44(55.0)$ & $19(55.9)$ & $9(50.0)$ & $16(57.1)$ \\
\hline Any anticholinergic inhalers & $55(68.8)$ & $26(76.5)$ & $10(55.6)$ & $19(67.9)$ \\
\hline Any inhaler & $80(100.0)$ & $34(100.0)$ & $18(100.0)$ & $28(100.0)$ \\
\hline
\end{tabular}

Abbreviations: ICS, inhaled corticosteroids; LABA, long acting beta2 agonist.

is not used, practitioners use smoking history and clinical features for COPD diagnosis which lacks sensitivity. ${ }^{17}$ Additionally, spirometry differentiates between asthma and COPD which have different therapy goals and treatment plans. Reliance on nonspecific symptoms of dyspnea, cough,

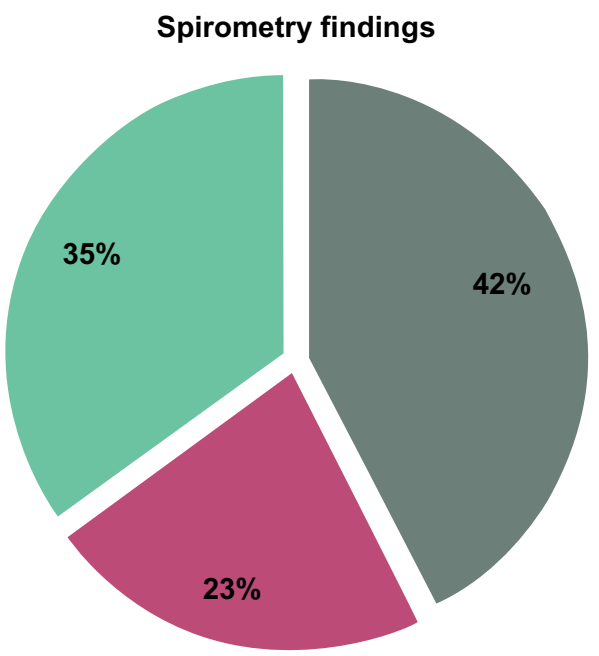

No obstruction

Reversible obstruction

Non-reversible obstruction

Figure I Spirometry findings of patients with previous chronic obstructive pulmonary disease or anticholinergic inhalers $(n=80)$. and wheezing has resulted in health practitioners responding to two physiologically different diseases in the same manner. ${ }^{5,18,19}$ Inappropriate diagnosis leads to inappropriate symptom management and ignorance of underlying etiology. Unnecessary medications, poor management, and side effects associated with inappropriate medications increase the overall cost while potentially harming the patient. Known side effects associated with medications used by these patients may include angioedema, anaphylaxis, bronchospasm, arrhythmia, glaucoma, and adrenal suppression. ${ }^{20}$

The presence of over diagnosis in the current series of COPD patients $-42.5 \%$ - is consistent with reports outside of the US. International studies have examined the prevalence of COPD misdiagnosis due to lack of spirometry. COPD misdiagnosis was $31 \%$ in Australia, ${ }^{7} 28.6 \%$ in Belgium, ${ }^{9} 25.8 \%$ in Norway, ${ }^{21} 27.2 \%$ in the UK, ${ }^{22}$ and $49.8 \%$ in Greece. ${ }^{23}$ One study which combined patients from Colorado and Scotland documented a 51.6\% COPD misdiagnosis (Table 2). ${ }^{10}$

Studies vary in their definition of reversible obstructions. Due to literature inconsistency and discrepant guidelines, we decided to only consider results that showed no obstruction $\left(\mathrm{FEV}_{1} / \mathrm{FVC} \geq 0.7\right)$ as a clear COPD misdiagnosis. Although being diagnosed with or treated for COPD, $42.5 \%$ of our patients showed no obstruction on spirometry. Given that some of the patients who had reversible obstruction could 
Table 2 Comparison of studies that highlighted the magnitude of chronic obstructive pulmonary disease over diagnosis

\begin{tabular}{|c|c|c|c|c|c|c|}
\hline Author & Year & Country & $\begin{array}{l}\text { Sample } \\
\text { size }\end{array}$ & Setting & $\begin{array}{l}\text { Rate of COPD } \\
\text { over diagnosis }\end{array}$ & $\begin{array}{l}\text { Variables associated } \\
\text { with COPD over } \\
\text { diagnosis }\end{array}$ \\
\hline Walters et $\mathrm{al}^{7}$ & 2011 & Australia & 341 & $\begin{array}{l}\text { Ambulatory } \\
\text { practices }\end{array}$ & $31 \%$ & $\begin{array}{l}\text { Higher BMI and } \\
\text { self-reported allergic } \\
\text { rhinitis or hay fever }\end{array}$ \\
\hline Buffels et al ${ }^{9}$ & 2012 & Belgium & 312 & $\begin{array}{l}\text { Family medicine } \\
\text { teaching practices }\end{array}$ & $28.6 \%$ & Not done \\
\hline Melbye et $\mathrm{al}^{21}$ & 2011 & Norway & 376 & $\begin{array}{l}\text { General office } \\
\text { practices }\end{array}$ & $25.8 \%$ & Not reported \\
\hline Jones et $\mathrm{a}^{22}$ & 2008 & United Kingdom & 580 & $\begin{array}{l}\text { Primary care } \\
\text { practices }\end{array}$ & $27.2 \%$ & Not reported \\
\hline Sichletidis et $\mathrm{a}^{23}$ & 2007 & Greece & 319 & $\begin{array}{l}\text { Primary care } \\
\text { centers }\end{array}$ & $49.8 \%$ & Not done \\
\hline Tinkelman et al ${ }^{10}$ & 2006 & Scotland-US & 597 & $\begin{array}{l}\text { Primary care } \\
\text { centers }\end{array}$ & $51.6 \%$ & Not reported \\
\hline Ghattas et al & 2013 & US & 80 & $\begin{array}{l}\text { Primary care } \\
\text { practice }\end{array}$ & $42.5 \%$ & Not reported \\
\hline
\end{tabular}

Abbreviations: BMI, body mass index; COPD, chronic obstructive pulmonary disease.

have asthma and not COPD, prevalence of COPD misdiagnosis could be higher in this series. Since the only study performed in the US included patients from Scotland and Colorado, ${ }^{10}$ the prevalence of COPD misdiagnosis in the US remains unclear. Additionally, our results may be more representative of uninsured and underserved patients.

Lower European COPD misdiagnosis could be linked to emphasis on spirometry in ambulatory settings. ${ }^{18}$ Low utilization of spirometry in the US may be attributed to factors such as unawareness of the value of spirometry, lack of access, busy settings, and lack of device training. ${ }^{16}$ Another major challenge is provider perception of test uncertainty and the inability to interpret spirometry data. ${ }^{24}$ Incorporating training seminars to educate health professionals has shown promise, increasing spirometry use by $59 \%$ in a 3 month period following training. ${ }^{16}$

This study is the first to examine COPD misdiagnosis and prevalence of spirometry in a group of solely American patients. Study limitations include patient recall bias and data entry errors in the medical record. The current series was only referred for spirometry based on the individual provider's preferences to manage uncontrolled COPD or to confirm previously diagnosed COPD. Therefore, current data may not be representative and should be viewed as a pilot investigation to assess COPD in an underserved population. However, current data suggest that there is a problem with COPD over diagnosis in the underserved population and that problem could be significant due to the lack of resources. The underserved population may have more risk for fragmented care and lack of access to health care resources which could make them more vulnerable to such issues. More research in this area is needed, especially in the underserved population. Justification of offering free or discounted spirometry service could be explored based on anticipated cost avoidance of misdiagnosed COPD cases.

\section{Conclusion}

Symptoms and smoking history are insufficient to diagnose COPD. Prevalence of COPD over diagnosis in uninsured patient populations may be higher than previously reported. Confirming COPD diagnosis with spirometry is essential to avoid unnecessary and potentially harmful over treatment.

\section{Disclosure}

The authors report no conflicts of interest in this work

\section{References}

1. Buist AS, McBurnie MA, Vollmer WM, et al; BOLD Collaborative Research Group. International variation in the prevalence of COPD (the BOLD Study): a population-based prevalence study. Lancet. 2007;370(9589):741-750.

2. Halpern MT, Stanford RH, Borker R. The burden of COPD in the USA: results from the Confronting COPD survey. Respir Med. 2003; 97 Suppl C:S81-S89.

3. Jemal A, Ward E, Hao Y, Thun M. Trends in the leading causes of death in the United States, 1970-2002. JAMA. 2005;294(10):1255-1259.

4. Barnes PJ, Kleinert S. COPD - a neglected disease. Lancet. 2004; 364(9434):564-565.

5. Global Strategy for the Diagnosis, Management and Prevention of COPD, Global Initiative for Chronic Obstructive Lung Disease (GOLD) 2011 [homepage on the Internet]. Available from: http://www.goldcopd.org/. Accessed August 20, 2013.

6. Jackson H, Hubbard R. Detecting chronic obstructive pulmonary disease using peak flow rate: cross sectional survey. BMJ. 2003;327(7416): 653-654. 
7. Walters JA, Walters EH, Nelson M, et al. Factors associated with misdiagnosis of COPD in primary care. Prim Care Respir J. 2011;20(4): 396-402.

8. Averame G, Bonavia M, Ferri P, et al; "Alliance Project" Study Group. Office spirometry can improve the diagnosis of obstructive airway disease in primary care setting. Respir Med. 2009;103(6):866-872.

9. Buffels J, Degryse J, Liistro G, Decramer M. Differential diagnosis in a primary care population with presumed airway obstruction: a real-life study. Respiration. 2012;84(1):44-54.

10. Tinkelman DG, Price DB, Nordyke RJ, Halbert RJ. Misdiagnosis of COPD and asthma in primary care patients 40 years of age and over. J Asthma. 2006;43(1):75-80.

11. Miller MR, Hankinson J, Brusasco V, et al. ATS/ERS Task Force. Standardisation of spirometry. Eur Respir J. 2005;26(2):319-338.

12. Pellegrino R, Viegi G, Brusasco V, et al. Interpretative strategies for lung function tests. Eur Respir J. 2005;26(5):948-968.

13. National Collaborating Centre for Chronic Conditions. Chronic obstructive pulmonary disease. National clinical guideline on management of chronic obstructive pulmonary disease in adults in primary and secondary care. Thorax. 2004;59 Suppl 1:1-232.

14. Schermer TR, Jacobs JE, Chavannes NH, et al. Validity of spirometric testing in a general practice population of patients with chronic obstructive pulmonary disease (COPD). Thorax. 2003;58(10):861-866.

15. Wen FQ, He B. [Interpretation of Global Strategy for the Diagnosis, Management and Prevention of Chronic Obstructive Pulmonary Disease (GOLD) (revised 2011).] Zhonghua Yi Xue Za Zhi. 2012;92(14):939-940. Chinese.

16. Kaminsky DA, Marcy TW, Bachand M, Irvin CG. Knowledge and use of office spirometry for the detection of chronic obstructive pulmonary disease by primary care physicians. Respir Care. 2005;50(12): 1639-1648.
17. Griffiths C, Feder G, Wedzicha J, Foster G, Livingstone A, Marlowe GS. Feasibility of spirometry and reversibility testing for the identification of patients with chronic obstructive pulmonary disease on asthma registers in general practice. Respir Med. 1999;93(12):903-908.

18. Celli BR. The importance of spirometry in COPD and asthma: effect on approach to management. Chest. 2000;117(Suppl 2):15S-19S.

19. National Asthma Education and Prevention Program. Expert Panel Report 3 (EPR-3): Guidelines for the Diagnosis and Management of Asthma-Summary Report 2007. J Allergy Clin Immunol. 2007; 120(Suppl 5):S94-S138.

20. Grimes GC, Manning JL, Patel P, Via RM. Medications for COPD: a review of effectiveness. Am Fam Physician. 2007;76(8):1141-1148.

21. Melbye H, Drivenes E, Dalbak LG, Leinan T, Hoegh-Henrichsen S, Ostrem A. Asthma, chronic obstructive pulmonary disease, or both? Diagnostic labeling and spirometry in primary care patients aged 40 years or more. Int J Chron Obstruct Pulmon Dis. 2011;6:597-603.

22. Jones RC, Dickson-Spillmann M, Mather MJ, Marks D, Shackell BS. Accuracy of diagnostic registers and management of chronic obstructive pulmonary disease: the Devon primary care audit. Respir Res. 2008;9:62.

23. Sichletidis L, Chloros D, Spyratos D, et al. The validity of the diagnosis of chronic obstructive pulmonary disease in general practice. Prim Care Respir J. 2007;16(2):82-88.

24. Bolton CE, Ionescu AA, Edwards PH, Faulkner TA, Edwards SM, Shale DJ. Attaining a correct diagnosis of COPD in general practice. Respir Med. 2005;99(4):493-500.
International Journal of COPD

\section{Publish your work in this journal}

The International Journal of COPD is an international, peer-reviewed journal of therapeutics and pharmacology focusing on concise rapid reporting of clinical studies and reviews in COPD. Special focus is given to the pathophysiological processes underlying the disease, intervention programs, patient focused education, and self management protocols.

\section{Dovepress}

This journal is indexed on PubMed Central, MedLine and CAS. The manuscript management system is completely online and includes a very quick and fair peer-review system, which is all easy to use. Visit http://www.dovepress.com/testimonials.php to read real quotes from published authors. 